See Article page 132.

\section{Commentary: The silver lining of coronary artery bypass grafting in the era of coronavirus disease 2019}

\author{
Abigail R. Benkert, MD, and \\ Oliver K. Jawitz, MD, MHS
}

The global coronavirus disease 2019 (COVID-19) pandemic has caused significant disruption of health care services. Cardiac surgery, a specialty heavily dependent on intensive care resources, has been especially influenced due to reallocations of these resources, including ventilators as well as intensive care beds and staff. ${ }^{1}$

Parcha and colleagues ${ }^{2}$ examine the risk of adverse outcomes among patients undergoing coronary artery bypass graft (CABG) surgery during the initial 9-month period of the COVID-19 pandemic. This retrospective crosssectional analysis compared clinical outcomes of patients undergoing $\mathrm{CABG}$ from 26 health care organizations during pre-COVID-19 and COVID-19 study periods. The primary end point evaluated was mortality within 30 days. Secondary end points included stroke, acute kidney injury, acute respiratory distress syndrome, and prolonged mechanical ventilation. During the 2020 COVID-19 study period, there was a $36 \%$ decline in CABG case volume. Propensityscore matching of 3569 patient pairs revealed similar odds of mortality by 30 days. The odds of secondary outcomes in the matched pairs were also similar. The investigators concluded that whereas CABG volume declined during the pandemic, CABG procedures have been performed safely, despite the resource limitations encountered during the pandemic.

From the Department of Surgery, Duke University Medical Center, Durham, NC. Disclosures: The authors reported no conflicts of interest.

The Journal policy requires editors and reviewers to disclose conflicts of interest and to decline handling or reviewing manuscripts for which they may have a conflict of interest. The editors and reviewers of this article have no conflicts of interest.

Received for publication April 16, 2021; revisions received April 16, 2021; accepted for publication April 19, 2021; available ahead of print May 10, 2021.

Address for reprints: Oliver K. Jawitz, MD, MHS, Department of Surgery, Duke University Medical Center, Box 3443, Durham, NC 27710 (E-mail: oliver.jawitz@ duke.edu).

JTCVS Open $2021 ; 6: 144-5$

2666-2736

Copyright (C) 2021 The Author(s). Published by Elsevier Inc. on behalf of The American Association for Thoracic Surgery. This is an open access article under the CC BY-NC-ND license (http://creativecommons.org/licenses/by-nc-nd/4.0/).

https://doi.org/10.1016/j.xjon.2021.04.011
Check for updates

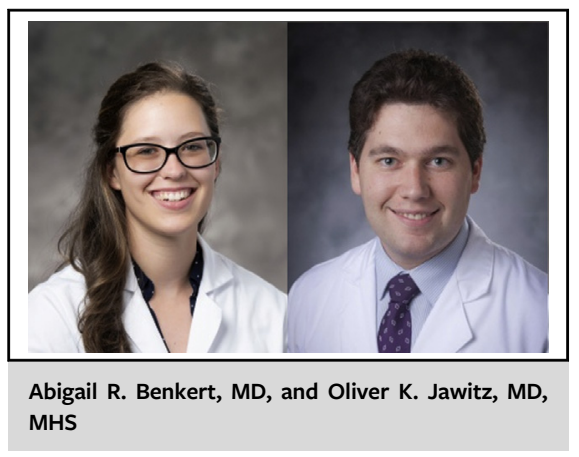

CENTRAL MESSAGE

Short-term post-CABG out-

comes appear to be relatively

unchanged during the COVID-19

pandemic. However, volume has

decreased significantly, and the

longer-term influence of delayed

care is yet to be seen.

The authors are to be congratulated for a well-written article. Due to limitations of the data available in the TriNetX database, a more granular analysis was not feasible, including evaluation of preoperative risk assessment as well as geographic differences. Nonrespiratory complications of COVID-19, such as thrombotic events, were not queried, which may be due to the low number of patients in the cohort identified as having COVID-19. Although the finding that $\mathrm{CABG}$ volume decreased during the COVID-19 pandemic is well-supported with other observational studies, ${ }^{3,4}$ the findings that postoperative outcomes are unchanged are in contrast to a larger study $(n=717,103)$ evaluating data from the Society of Thoracic Surgeons Adult Cardiac Surgery Database, ${ }^{3}$ which demonstrated an increased observed-to-expected mortality rate during the pandemic. Further studies evaluating the longitudinal effects of the ongoing COVID-19 pandemic are needed. We likely have not yet seen the broader influence of delayed and postponed cases.

\section{References}

1. Mohamed Abdel Shafi A, Hewage S, Harky A. The impact of COVID-19 on the provision of cardiac surgical services. J Card Surg. 2020;35:1295-7.

2. Parcha V, Kalra R, Glenn AM, Davies JE, Kuranz S, Arora G, et al. Coronary artery bypass graft surgery outcomes in the United States: impact of coronavirus 
disease 2019 (COVID-19) pandemic. J Thorac Cardiovas Surg Open. 2021;6: $132-43$.

3. Salenger R, Etchill EW, Ad N, Matthew T, Alejo D, Whitman G, et al. The surge after the surge: cardiac surgery post-COVID-19. Ann Thorac Surg. 2020;110:2020-5.
4. Nguyen TC, Thourani VH, Nissen AP, Habib R, Dearani JA, Crestanello JA, et al The effect of COVID-19 on adult cardiac surgery in the United States: analysis of the Society of Thoracic Surgeons Adult Cardiac Surgery Database. Presented at the 57th Annual Meeting of the Society of Thoracic Surgeons; January 29, 2021. 